\title{
Humoral Immune Response to the Anti-malaria Vaccine SPf66 in the Colombian Atrato River Region
}

\author{
TM Lopera/ ${ }^{+}$, M Restrepo, S Blair*, HI García**
}

\begin{abstract}
Instituto Colombiano de Medicina Tropical, A.A. 52162, Medellin, Colombia *Laboratorio de Hemoparásitos
**Centro de Investigaciones Médicas, Universidad de Antioquia, A.A. 1226, Medellín, Colombia
\end{abstract}

The immunogenicity of anti-malaria synthetic vaccine SPf66 was tested in a region of the Colombian middle Atrato river. The specific serum antibodies against SPf66 were quantified in vaccinees and placebo injected controls for a two-years period post-immunization. The frequency of individuals showing seroconversion of anti-SPf66 antibodies three months after completion of the immunization schedule was higher in vaccinees than in controls $(52.7 \%$ and $25.5 \%$, respectively, $p<0.01)$. However, an over than four-fold increase of the specific anti-SPf66 antibody titers was observed only in $1.4 \%$ of vaccinees and $0.2 \%$ of the controls $(p<0.01)$. The anti-SPf66 antibody titers augmented in vaccinees from first dose application to three months after the third dose, continuously decreasing thereafter to reach below baseline values two years after completion of the immunization schedule. The results show that SPf66 has very low immunogenicity and induces a short term humoral immune response (six months).

Key words: malaria vaccine - SPf66 - antibodies

The synthetic molecule SPf66, developed in Colombia (Patarroyo et al. 1987) to prevent Plasmodium falciparum malaria, is nowadays the antimalaria vaccine most frequently tested in human populations. The peptide has been tested in animal models and human volunteers subject to experimental challenge (Patarroyo et al. 1987, 1988) as well as in individuals from endemic areas in Colombia and other countries in America and Africa (Valero et al. 1993, Sempertegui et al. 1994, Teuscher et al. 1994).

SPf66 has been shown to induce production of specific IgG antibodies against the peptide in approximately $60 \%$ of vaccinees once immunization is completed, although such immunogenicity has not been associated to protection against malarial infections (Valero et al. 1993, Sempertegui et al. 1994, Teuscher et al. 1994).

Immunogenicity of the SPf66 vaccine has been expressed in terms of the relative frequency of positive individuals for specific $\operatorname{IgG}$ antibodies against the peptide one month after completion of the immunization schedule (Valero et al. 1993, Sempertegui et al. 1994, Noya et al. 1994). These

This study was supported by the Instituto Colombiano para el Desarrollo de la Ciencia y la Tecnología (COLCIENCIAS) and the Dirección Seccional de Salud de Antioquia, Colombia.

+Corresponding author: Fax: +574 - 26335 09. E mail: tlopera@catios.udea.edu.co

Received 19 August 1997

Accepted 7 May 1998 antibodies are known to recognize native proteins in the merozoite such as $135 \mathrm{Kd}, 83 \mathrm{Kd}$ and 115 Kd (Salcedo et al. 1991).

In addittion, several epitopes present in the SPf66 peptide have been identified in merozoite proteins that are important for invasion of erythrocytes such as EBA-175 (erythrocyte binding antigen) and PMMSA (protein merozoite major surface antigen) (Molano et al. 1992). This finding is supported by the observation of antibodies against the peptide in non-vaccinated populations from endemic areas (Valero et al. 1993, Noya et al. 1994, Teuscher et al. 1994). It is noteworthy that a correlation has also been found between the low $\operatorname{IgG}$ antibody response to the vaccine and the presence of HLA-DR4 allele in vaccinees (Murillo et al. 1991).

In order to further test the immunogenicity of the SPf66 vaccine, a double-blind randomized placebo control study was carried out in a region of the Colombian middle Atrato river, known to be a high endemic area for P. falciparum infection. A two year follow up study was performed on the specific antibodies against SPf66 in vaccinees and placebo injected controls. The correlation between the response to the vaccine and history of a previous natural infection through titration of $\mathrm{IgG}$ antibodies against $P$. falciparum is also described.

\section{SUBJECTS AND METHODS}

Study area - The present work was carried out in urban areas of Vigía del Fuerte and Bellavista, towns located along the banks of the Atrato river in northwestern Colombia. A tropical rain forest 
climate predominates in the area, with a mean temperature of $28^{\circ} \mathrm{C}$, and a $80 \%$ relative humidity.

Population is mainly african-black with mestizo and native minorities who earn their living from agriculture, fishing, and gold mining. Most people live in wooden, zinc-roofed palafitte-houses to prevent from flooding in rainy periods of the year. From 1987 to 1992, the study area showed an annual parasitic incidence (API) ranging from 97 to 308 cases per 1,000 inhabitants and an annual average incidence of 178/1.000. During the study period, from 1992 to 1995 , the API in this area decreased 108/1000 inhabitants to $<5 / 1000$. In that period, $P$. falciparum cases were more numerous than $P$. vivax cases with an average ratio of $11 / 1$.

Study population - The reference population included over one-year old individuals residents in urban areas of Vigía del Fuerte and Bellavista, identified through a census carried out in July 1992 before the beginning of the study. Individuals were registered according to neighborhoods, since there were differences among them concerning the type of building, the distance from mosquito-breeding sites and flooding degree during rainy periods of the year.

The study population included individuals who gave a previously written consent after being sufficiently informed about aims, risks and benefits derived from the study. Subjects with the following conditions were excluded: history of bronchial asthma, clinical diagnosis of malaria confronted by parasitic count at the moment of vaccination, acute illness, children 1 to 4 years of age with any transmittable disease, subjects having lived less than six months in the endemic area, and pregnant women. Eligible subjects were randomly assigned to either of two groups: one receiving the antimalaria SPf66 vaccine and the other receiving aluminium hidroxide as placebo.

Vaccination - Individuals were immunized with the synthetic peptide SPf66, batch \# 8, produced by the Instituto de Inmunología, Bogotá (Colombia) under good manufacturing practice, by means of the solid-phase chemical synthesis method (Houghten 1985, Valero et al. 1993, Sempertegui et al. 1994).

Five-years old individuals and over received a vaccine dose of $2 \mathrm{mg}$ synthetic protein adsorbed onto $1.25 \mathrm{mg}$ aluminium hydroxide. Children 1 to 4 years of age received half of these concentrations per dose. The concentration of aluminium hydroxide used as placebo was $1.25 \mathrm{mg} / \mathrm{ml}$ in individuals 5 years old and over, half of this concentration was used as placebo in children 1 to 4 years.

All individuals were given three doses of the SPf66 peptide or placebo at zero, one and six months, according to the immunization schedule established by Rocha et al. (1992). Both vaccine and placebo were donated by manufacturers, later reconstituted in identical two-letter code labeled vials which were kept refrigerated at $4^{\circ} \mathrm{C}$ before use. Vaccine and placebo codes were only known by us until the final analysis of the results.

Serological follow-up and antibody determination - During immunization, blood samples were taken just prior to application of every vaccine dose, at zero, one and six months and then there were scheduled measurements at three, six, eighteen and twenty four months post-immunization.

Blood samples were obtained by finger puncture on four $1.5 \mathrm{~cm}$ filter paper discs (Whatman \#3MM CHr). These were room-temperature dried and kept at $4^{\circ} \mathrm{C}$ for transportation to the laboratory where they were finally frozen at $-20^{\circ} \mathrm{C}$ until processing. For serologic tests, blood was reconstituted from filter paper discs with $492 \mathrm{ml}$ of PBS $\mathrm{pH} 7.2$, containing $1 \%$ of Tween ${ }^{\mathrm{TM}} 80$ for $24 \mathrm{hr}$ at $4^{\circ} \mathrm{C}$, which corresponded to an initial dilution of $1: 16$.

IgG antibodies against $P$. falciparum were detected by means of indirect immunofluorescence assay (IFA) (Lopez-Antuñano \& Schmunis 1988). The IFA antigen was obtained from continuous culture of $P$. falciparum strain FCB2 syncronized by the Lambrios' technique (Lambrios \& Vanderberg 1979). This antigen was plate-seeded at a concentration of $5 \%$ hematocrite with $1 \%$ parasitaemia, air dried and blocked with $3 \%$ of blotto in PBS.

The plates were then incubated in the presence of the diluted blood samples for $30 \mathrm{~min}$ at $37^{\circ} \mathrm{C}$. After washing, fluorescein-labeled anti-human IgG (BioMérieux, France) (1:400) was added to the plates for $30 \mathrm{~min}$ at $37^{\circ} \mathrm{C}$. The sample analysis was carried out in a Nikon fluorescence microscope with B2A filters and the cutoff point dilution was 1:16.

Specific IgG antibodies against the synthetic peptide SPf66 were detected by means of FAST ${ }^{\mathrm{TM}}$ ELISA (Falcon assay screening test). This technique was performed as described by Salcedo et al. (1991). Two-fold dilutions of the eluted sample were previously prepared in PBS containing 1\% of Tween ${ }^{\mathrm{TM}} 20$ and $5 \%$ of milk and the plates were incubated for $1 \mathrm{hr}$ at room temperature. After washing, peroxidase conjugated anti-human IgG (Sigma Chemical Co., USA) was added to the plates. Optical density was read at $620 \mathrm{~nm}$ in a Titertek Multiskan 340 MK II spectrofotometer (Labsystem and Flow Labs, Finland). Antibody titer was considered to be the highest dilution ( $\left.{ }^{3} 1: 100\right)$ of the eluted fraction with optical density higher than 0.1 .

Statistical analysis - Seroconversion was considered as the increase of anti-SPf66 antibody ti- 
ters during or after immunization as compared to baseline titers. To assess such variation a seroconversion index (SCI) was defined as the ratio of the antiboby titers at every scheduled measurement to baseline antibody titers. To estimate the SCI, a 1:50 value was assigned to the samples with negative pre-vaccination titers. Seroconversion was taken into consideration with index values $>1.0$.

The increase in the number of titer dilutions was determined for all subjects who seroconverted three months after the third dose. To assess the production kinetics of anti-SPf66 IgG-titers and anti- $P$. falciparum IgG-titers, a logarithmic transformation of titers was done $(\mathrm{x}+1)$ and then a geometric mean for each time point was calculated. For this analysis, negative samples were assigned a zero value.

\section{RESULTS}

Population baseline conditions - A total of 2,157 individuals met the vaccination criteria, of which 1,280 (59.3\%) gave a written consent to be included in the study. Six hundred and thirty- two individuals (49.4\%) received the first dose of SPf66 and $648(50.6 \%)$ received the first dose of placebo. The three-dose schedule was completed by 994 subjects $(77.7 \%)$, of which 500 received the vaccine and 494 were given the placebo; however, only 421 subjects of the vaccine group and 420 of the placebo group completed the serologic follow up.

Distribution of individuals that received the complete immunization plan was similar concerning age, sex, history of malarial infection, and prevalence of positive titers of both anti-SPf66 and anti-parasite antibodies ( $>>0.01)$ in both vaccine and placebo groups (Table I).

TABLE I

Baseline characteristics of study population

\begin{tabular}{lcc}
\hline & $\begin{array}{c}\text { Vaccinees } \\
\mathrm{n}=500\end{array}$ & $\begin{array}{c}\text { Placebo } \\
\mathrm{n}=494\end{array}$ \\
\hline Age groups (years) & $\%$ & $\%$ \\
$1-4$ & & \\
$5-9$ & 11.8 & 12.6 \\
$10-14$ & 19.6 & 20.1 \\
$\quad 15-44$ & 18.0 & 18.6 \\
$\quad 45$ or more & 38.4 & 36.7 \\
Men $\quad 12.2$ & 12.0 \\
Women & 44.2 & 46.2 \\
Previous malaria episodes & 55.8 & 53.8 \\
Plasmodium falciparum & 44.9 & 42.7 \\
IgG antibody & 41.5 & 41.0 \\
SPf66 IgG antibody & & \\
\hline
\end{tabular}

A higher percentage of positivity for anti-parasite IgG antibodies as compared to those against the synthetic peptide SPf66 was observed in both groups before immunization. The anti-parasite antibody titers by IFA were directly correlated to age (correlation coeficient $=0.37$ I.C. $95 \% 0.31-0.42$, $\mathrm{p}<0.05)$. On the contrary, there was no such correlation for anti-SPf66 antibodies.

Seroconversion - One month after the first-dose application of both vaccine and placebo, seroconversion was detected in $47 \%$ of vaccinees and $42 \%$ of placebo subjects $(\mathrm{p}=0.1)$. Three months after completion of the vaccination schedule, seroconversion percentages were $52.7 \%(222 / 421)$ in vaccinees and $25.5 \%(107 / 420)$ in the placebo group $(\mathrm{p}<0.001)$. Seroconversion was not present in any subject 6 and 18 months after the third dose. From the individuals with seroconversion three months after the third dose in the vaccine group (222), $30 \%$ continued with a positive index at six months after the third dose and $2 \%$ at eighteen months after the third dose. There were no subjects with positive index twenty-four months after the vaccination schedule was completed.

A higher seroconversion frequency was detected in subjects who were negative for anti-SPf66 antibodies prior to immunization (Table II). Most seroconverters from both vaccine and placebo groups showed a single-dilution increase in antiSPf66 antibody titers. Seroconversion with more than a two-dilution increase in antibody titers was higher in vaccinees than in placebo subjects $(\mathrm{p}<0.01)$ (Fig. 1).

No correlation was found between anti-SPf66 antibody seroconversion after either the first or the third vaccine dose and the presence or absence of anti-parasite antibodies prior to vaccination ( $p>0.01)$. There was no correlation between seroconversion three months after the third dose and history of a malarial episode before the study period $(\mathrm{p}>0.01)$.

\section{TABLE II}

Frequency of seroconversion three months after the third dose according to initial state of SPf66 antibodies

\begin{tabular}{lrccrcr}
\hline Initial state & \multicolumn{4}{c}{ Seroconversion } \\
\cline { 2 - 7 } Ac - SPf66 & \multicolumn{3}{c}{ Vaccinees } & \multicolumn{3}{c}{ Placebos } \\
& No. & $(\%)$ & $\mathrm{n}$ & No. & $(\%)$ & $\mathrm{n}$ \\
\hline Negative & 182 & $(58.3)$ & 312 & 97 & $(29.1)$ & 333 \\
Positive & 40 & $(36.7)$ & 109 & 10 & $(11.5)$ & 87 \\
\hline Total & 222 & $(52.7)$ & 421 & 107 & $(25.5)$ & 420 \\
\hline n: subjects in every cell; & no seroconversion: vaccinees \\
199, placebo 313.
\end{tabular}




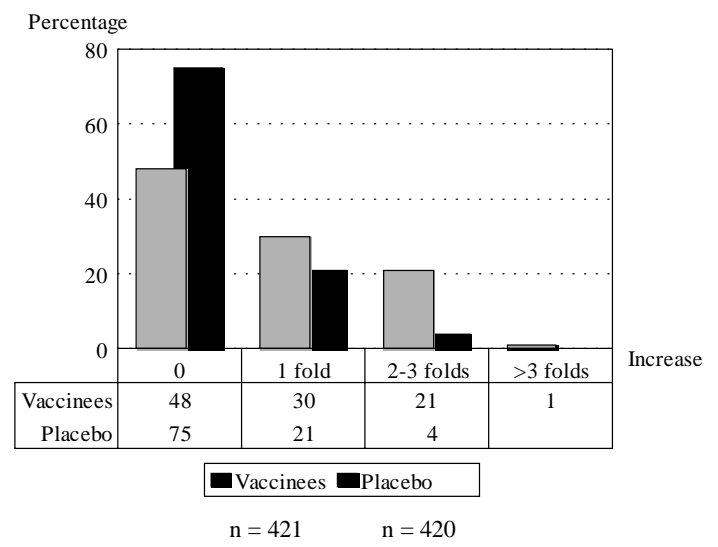

Fig. 1: increase in SPf66 antibody titers three months after the third dose.

Nineteen percent $(96 / 500)$ of vaccinees and $28 \%$ (139/494) of placebo subjects showed no alteration of their baseline anti-SPf66 antibody titers during the study, neither during the course of immunization nor during the subsequent two-year follow-up period.

Kinetics of production of anti-SPf66 and antiP. falciparum antibodies - A significant increase in the average of anti-SPf66 antibody titers in vaccinees was observed one month after the first dose of vaccine $(p<0.01)$. The response of antiSPf66 antibodies was higher in vaccinees than in placebo individuals until six months after completion of the immunization schedule, when it began to descend progressively to reach below-baseline average values two years after the third dose (Fig. 2).

In contrast, the comparison of anti- $P$. falciparum antibody titers behavior, both in vaccinees and placebo individuals showed no statistical significant difference because of vaccination. Averages of these titers remained unaltered during the course of immunization and then decreased progressively during the subsequent follow-up period (Fig. 3).

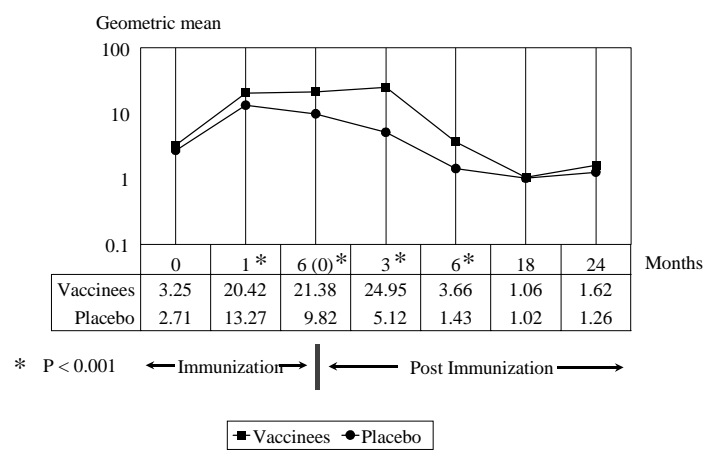

Fig. 2: production kinetics of anti-SPf66 antibodies in vaccinees and placebo subjects.

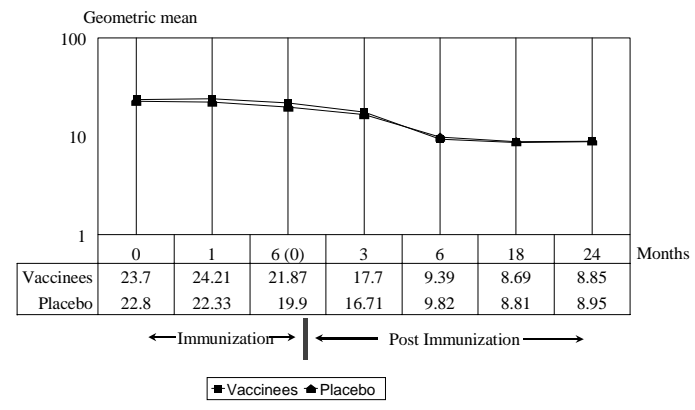

Fig. 3: production kinetics of anti-Plasmodium falciparum antibodies in vaccinees and placebo subjects.

\section{DISCUSSION}

This is the first study that measures the SPf66 peptide immunogenicity, by means of the determination of specific $\operatorname{IgG}$ antibody titers, in a vaccinated population with a two-year follow up period. In addition, this is the first time that specific antibody response against the SPf66 peptide is correlated to personal history of a previous contact with natural infection.

The decrease of malaria incidence registered in the study area during the present study (unpublished observations) may be considered an advantage to assess the immunogenicity of the SPf66 vaccine by excluding the effect of natural infection on the production of cross reactive anti-SPf66 antibodies.

The percentage of specific anti-peptide antibody carriers three months after the third dose in the SPf66 vaccinated group (63.1\%) is similar to that reported in other studied populations in Ecuador (57\%) (Sempertegui et al. 1994) and Venezuela (60.4\%) (Noya et al.1994), but higher than that observed in a study carried out in La Tola (Colombia) (33\%) (Valero et al. 1993). This can be explained by the fact that in the latter study the cutoff point used for the determination of antibody titers was 0.2 (Valero et al. 1993), unlike the 0.1 cutoff point used by the other studies (Sempertegui et al. 1994, Noya et al. 1994).

Although the seroconversion index was calculated at every scheduled measurement, the following two measurements were considered as the most important for the analysis of the results: one month after first-dose application, because it permits to analyse humoral response to the first antigenic stimuli, and three months after third-dose application because this was the first measurement before the vaccination schedule was completed.

It is noteworthy that a significant higher seroconversion index average was observed for the present study population (14.19 for vaccinees and 10.96 for the placebo group) as compared to that 
obtained in a population under 15 years old (8.3 for vaccinees and 0.7 for the placebo group) (Alonso et al. 1994). This can be explained by the fact that the seroconversion index is an absolute value measuring changes in antibody titers and subtracting the effect produced by antibody baseline values. This interpretation suggest that immunization in Vigia del Fuerte and Bellavista had a higher effect on anti-SPf66 antibody baseline titers as compared to that carried out in Africa for both vaccinees and the placebo group.

Although the synthetic molecule was immunogenic in vaccinees, we think this immunogenicity was poor since the majority of the specific seroconversion observed three months after the third dose was characterized by a single-dilution increase in anti-SPf66 antibody titers.

Interestingly, in this study the group of subjects with pre-vaccination anti-SPf66 antibody had less frequency of seconversion three months after the last vaccine dose (Table II). Several studies have demonstrated the presence of anti-SPf66 antibodies in non-vaccinated individuals from endemic areas (Valero et al. 1993, Leach et al. 1995). It is logical to think that these antibodies may modify the course of humoral immune response to the SPf66 peptide. One of the mechanisms to explain this fact could be that SPf66 antibodies induced by natural infection neutralize the antigen at the moment of vaccination, inhibiting humoral immune response, in a similar way to the inhibition of the response to $\mathrm{Rh}$ antigens during pregnancy (Abbas 1995). If this hypothesis is true, a different strategy of vaccination for seropositive subjects in endemic areas should be designed.

A significant number of individuals from both groups did not respond to immunization at anytime of the study. Several authors have reported a correlation between low response of IgG antibodies against the peptide SPf66 and presence of HLA II-specific alleles such as DR4 (Murillo et al. 1991), DRB1*15 and DQB1*0601 (Beck et al. 1995). This means that in any vaccinated population it is not unusual to expect a variable percentage of low responders, which depends on the distribution of these alleles in every population.

A comparison made between the averages of anti-SPf66 antibody titers in vaccinees and placebo controls at anytime during the study showed that the synthetic peptide immunogenicity begins after the first dose of vaccine, but it does not last more than six months after completion of the immunization schedule. An effect of natural infection on the humoral immune response to the SPf66 peptide should not, however, be ruled out due to crossreactivity between both types of antigenic stimuli as shown by the relatively high frequency of anti-
SPf66 antibodies before vaccination in individuals from most study populations (Valero et al. 1993, Sempertegui et al. 1994, Leach et al. 1995). The decrease of infection incidence in the middle Atrato river area probably affected the levels of specific antibodies against the peptide as well as those against the parasite.

The average of specific anti-SPf66 antibody titers ninety days after the third dose is lower in this study (25.03 in vaccinees and 5.13 in controls) as compared to that obtained in the studies carried out in Tanzania (Alonso et. al. 1994) and Gambia (Leach et al. 1995, D' Alessandro et al. 1995). This difference could be explained by a greater prevalence of such antibodies observed before vaccination in the latter communities as well as to differences in measurement times, since in the African studies the determination of $\operatorname{IgG}$ antibodies was carried out one month after the third dose.

Presumably, vaccinees and controls were equally subject to natural infection during the study. Failure to find an association between pre-vaccination IFA data or history of malaria infection with seroconversion three months after completion of immunization suggests that the response to the vaccine was not related to individuals' previous contact with natural infection.

This lack of association, together with the percentage of non-responders found in this study point to the conclusion that SPf66 peptide specific response is not related to external factors but rather to genetic individual characteristics.

Finally, according to the data presented here, it can be concluded that the SPf66 vaccine shows very low capacity to induce humoral immunity. Therefore, the characteristics of the cellular immune response induced by the SPf66 vaccine must be determined in order to shed ligth on the understanding of the mechanisms of protection against natural $P$. falciparum infection.

\section{ACKNOWLEDGMENTS}

To the communities from Vigia del Fuerte and Bellavista for participating in this study. To Dr Manuel E Patarroyo, Dr Roberto Amador and his staff from the Instituto de Inmunología, Santa Fe de Bogotá, for donating the SPf66 vaccine, for preparation of plates for IFA and technical assistance in serological testing. To Dr Juan Carlos Dib and staff of the Instituto Colombiano de Medicina Tropical, Medellin, Colombia. To Dr Gustavo Zapata and the Research Group of Translation and Terminology from School of Languajes, University of Antioquia.

\section{REFERENCES}

Abbas AK, Litchman AH, Pober JS 1995. Inmunologia Celular y Molecular, 2nd ed., WB Saunders Company, Madrid, 246 pp. 
Alonso PL, Smith T, Armstrong JRM, Schellenberg, Massanja H, Mwankusye S 1994. Randomised trial of efficacy of SPf66 vaccine against $P$. falciparum malaria in children in southern Tanzania. Lancet 344: 1175 -1181.

Beck HP, Felger I, Barker M, Bugawan T, Genton B, Alexander N, Jazwinska E, Erlich H, Alpers M 1995. Evidence of HLA class II association with antibody response against the malaria vaccine SPf66 in a naturally exposed population. Am J Trop Med Hyg 53: 284-288.

D'Alessandro U, Leach A, Drakeley CJ, Bennett S, Olaleye BO, Fegan GW, Jawara M, Langerock P, George MO, Targett GAT, Greenwood BM 1995. Efficacy trial of malaria vaccine SPf66 in Gambian infants. Lancet 346: 462-467.

Houghten RA 1985. General method for the rapid solidphase synthesis of the large numbers of peptides: Specificity of antigen-antibody interaction of the level of individual aminoacids. Proc Natl Acad Sci USA 82: 5131.

Lambrios C, Vanderberg J 1979. Sinchronization of $P$. falciparum erythrocyte stages in culture. J Parasitol 65: 418-420.

Leach A, Drakeley CJ, D Alessandro U, Fegan GW, Bennett S, Ballou WR, Targett GAT, Greenwood BM 1995. A pilot safety and immunogenicity study of malaria vaccine SPf66 in Gambian infants. Parasite Immunol 17: 441-444.

Lopez-Antuñano FJ, Schmunis G 1988. Diagnostico de Malaria, Publicacion Cientifica 512, OPS/OMS, 8696 pp.

Molano A, Segura C, Guzman F, Lozada D, Patarroyo ME 1992. In human malaria protective antibodies are directed mainly against the Lys-Glu Lys motif of the synthetic vaccine SPf66. Parasite Immunol 14: 111-124.

Murillo LA, Rocha CL, Mora AL, Kalil J, Goldenberg AK, Patarroyo ME 1991. Molecular analysis of HLA DR4 beta 1 gene in malaria vaccinees. Typing and subtyping by PCR technique an oligonucleotides. Parasite Immunol 13: 201-210.

Noya GO, Gabaldon BY, Alarcon de Noya B, Borges R, Zerpa N, Urbaez JD, Madonna A, Garrido ME, Jimenez MA, Garcia P, Reyes I, Prieto W, Colmenares C, Pabòn R, Barraez T, G de Caceres
L, Godoy N, Sifontes R. 1994. A population-based clinical trial with the SPf66 synthetic P. falciparum malaria vaccine in Venezuela. J Infec Dis 170: 396402.

Patarroyo ME, Amador R, Clavijo P, Moreno A, Guzman F, Romero P, Tascon R, Franco A, Murillo LA, Ponton G, Trujillo G 1988. A synthetic vaccine protects humans against challenge with asexual blood stages of P. falciparum malaria. Nature 332: 358361.

Patarroyo ME, Romero P, Torres M, Clavijo P, Moreno A, Martinez A, Rodriguez R, Guzman F, Cabezas E 1987. Induction of protective inmunity against experimental infection with malaria using synthetic peptides. Nature 328: 629-632.

Rocha CL, Murillo LA, Mora AL, Rojas M, Franco L, Cote J 1992. Determination of the immunization schedule for field trials with the synthetic malaria vaccine SPf66. Parasite Immunol 14: 95-109.

Salcedo M, Barreto L, Rojas M, Moya R, Cote J, Patarroyo ME 1991. Studies of the humoral inmune response to a synthetic vaccine against $P$. falciparum malaria. Clin Exp Immunol 84: 122-128.

Sempertegui F, Estrella B, Moscoso J, Piedrahita-C L, Hernandez D, Gaybor J, Naranjo P, Mancero O, Arias S, Bernal R, Córdoba ME, Suarez J, Zicker F 1994. Safety, inmunogenicity and protective effect of the SPf66 malaria synthetic vaccine against $P$. falciparum infection in a randomized double-blind placebo-controlled field trial in an endemic area of Ecuador. Vaccine 12: 337-342.

Teuscher T, Armstrong-Schellenberg JRM, Bastos de Acevedo I, Hurt N, Smith T, Hayes R, Masanja H, Silva Y, Lopez MC, Kitua A, Kilama W, Tanner M, Alonso PL 1994. SPf66, a chemically synthesized subunit malaria vaccine, is safe and immunogenic in Tanzanians exposed to intense malaria transmission. Vaccine 12: 328-336.

Valero M, Amador R, Galindo C, Figueroa J, Bello MS, Murillo LA, Mora AL, Patarroyo G, Rocha CL, Rojas M, Aponte JJ, Sarmiento LE, Losada DM, Coronell CG, Ortega NM, Rosas JE, Alonso PL, Patarroyo ME 1993. Vaccination with SPf66, a chemically synthetized vaccine, against $P$. falciparum malaria in Colombia. Lancet 341: 705 710. 